Originalveröffentlichung in: Lermer, Andrea ; Shalem, Avinoam (Hrsgg.): After one hundred years : the 1910 exhibition "Meisterwerke muhammedanischer Kunst" reconsidered, Leiden 2010, S. 333-356 (Islamic history and civilization ; 82)

LE CORBUSIER UND SEIN ,VOYAGE D’ORIENT‘ 1911. EINFLÜSSE ISLAMISCHER BAUKUNST AUF DAS WERK DES ARCHITEKTEN IN DER ZEIT DER KLASSISCHEN MODERNE

\title{
Steffen Krämer
}

Zwischen Mai und Oktober 1911 unternahm der Schweizer Architekt Charles-Édouard Jeanneret, der sich ab 1920 Le Corbusier nannte, mit seinem Freund Auguste Klipstein eine Reise, die ihn von Prag ausgehend über den Balkan in die Türkei, nach Griechenland und dann Italien führte. ${ }^{1}$ Um das Unternehmen zu finanzieren, schrieb der damals erst 24jährige Architekt eine Serie von Artikeln, die auf seinen während der Reise erstellten Notizen basierten. Diese Artikel und die Einträge in seinen Reisetagebüchern wie auch Briefe, die er in jener Zeit an seine Freunde und Familie schrieb, hat Corbusier später unter dem Titel eines Voyage d'Orient zusammengefasst. Erstmals publiziert wurden große Teile dieses umfangreichen Textmaterials allerdings erst 1966 und damit ein Jahr nach dem Tod des Architekten. ${ }^{2}$ Eine vollständige Ausgabe der insgesamt sechs Tagebücher dieser Reise konnte erst in den 1980er Jahren veröffentlicht werden, nachdem mehrere, bis dahin noch fehlende Teile wieder aufgetaucht waren. ${ }^{3}$ Neben diesen Texten hat Corbusier eine Vielzahl von Skizzen gezeichnet, Fotografien erstellt und Postkarten gesammelt, so dass seine Reise in unterschiedlichen Informationsmedien dokumentiert ist. Text und Bild ergänzen sich somit auf sinnfällige Weise.

Corbusiers Orientreise wäre aber lediglich als frühes Intervall seiner Biographie interessant, hätte er nicht eine Vielzahl persönlicher Eindrücke und Erkenntnisse, die er während dieser fünf Monate gewonnen hatte, in seiner Architekturtheorie verarbeitet. Hierbei handelt es sich um drei frühe Schriften des Architekten: Vers une

${ }_{1} \mathrm{Zu}$ Corbusiers Reise und seinen Reisetagebüchern, -artikeln und -notizen siehe Curtis 1987, S. 36-41; Le Corbusier 1987b, S. 9-25; ders. 1991, S. 17-20; Gresleri 1991, S. 25-79; Jencks 2000, S. 66-87.

${ }^{2}$ Le Corbusier 1987a; Žaknić 1987. Zur posthumen Veröffentlichung von Corbusiers Voyage d'Orient siehe Curtis 1987, S. 37; Gresleri 1991, S. 7; Jencks 2000, S. 70.

${ }^{3}$ Zur vollständigen Ausgabe der insgesamt sechs Reisetagebücher von Corbusiers ,Voyage d'Orient's siehe Le Corbusier 1987b, S. 26-175. 
architecture von 1923, Urbanisme und L'art décoratif d'aujourd'hui, beide von $1925 .{ }^{4}$ Beschreibungen und Analysen orientalischer Baukunst wurden darin ebenso übernommen wie Abbildungen seiner Zeichnungen und Fotos. Vor allem die zwei erstgenannten Veröffentlichungen bilden die theoretische Grundlage für Corbusiers weiteren Schaffensprozess zumindest bis zum Ende der 1930er Jahre. Fast zwangsläufig resultiert daraus die Schlussfolgerung, dass Corbusiers frühe Erfahrungen mit der islamischen, vorwiegend osmanischen Architektur, die er auf seiner Reise kennenlernte und mit der er sich zuvor nur wenig beschäftigt hatte, für seinen weiteren Werdegang als Architekt und Theoretiker nicht nur sinnvoll, sondern auch notwendig waren. ${ }^{5}$

Die sieben Wochen in Istanbul ab Mitte Juli 1911 waren für Corbusier der Höhepunkt seiner Reise. ${ }^{6}$ Bereits Ende Juni hatten er und sein Freund Klipstein das türkische Edirne an der Grenze zu Griechenland besucht, jenes frühere Adrianopel, das vom mittleren 14. Jahrhundert bis zur Mitte des 15. Jahrhunderts Hauptstadt des osmanischen Reiches war. ${ }^{7}$ Während ihres Aufenthaltes in Istanbul unternahmen sie Ende August eine Exkursion nach Bursa, das vor Adrianopel, von 1335-1365, die osmanische Hauptstadt gewesen war. Istanbul, Edirne und Bursa waren damit die drei urbanen Zentren, die Corbusier besuchte und mit deren historischer wie zeitgenössischer Baukunst er sich intensiv auseinandersetzte. Das Spektrum seiner Beschäftigungen war dabei erstaunlich groß und reichte von umfassenden Analysen der städtischen Friedhöfe und Bazare bis zur genauen Schilderung eines türkischen Cafés mit seinem orientalischen

\footnotetext{
${ }^{4}$ Im Text wird bei den zwei erstgenannten Schriften auf die deutsche Übersetzung, bei der letztgenannten auf die Reprint-Ausgabe von 1959 Bezug genommen; siehe dazu Le Corbusier 1982; ders. 1979; ders. 1959.

${ }^{5}$ Während seines Münchner Aufenthaltes 1910 besuchte Le Corbusier Mitte September auch die Ausstellung „Meisterwerke muhammedanischer Kunst", über die er in seiner 1912 verfassten Schrift Étude sur le mouvement d'art décoratif en Allemagne berichten sollte. Zu Corbusiers Münchner Aufenthalt, zu seinem Besuch der Ausstellung und zu deren Erwähnung in seiner frühen Schrift siehe Gresleri 1991, S. 28-36; Kries 2008, S. 36, 174, 177. Den Hinweis sowohl auf Corbusiers Besuch der Münchner Ausstellung als auch auf die eben genannte neueste Fachliteratur verdankt der Autor Frau Dr. Annette Hagedorn, Berlin.

${ }^{6}$ Siehe dazu Le Corbusier 1987b, S. 23; Gresleri 1991, S. 59.

7 Zum historischen Status von Edirne, dem früheren Adrianopel, und im Folgenden zu Bursa siehe Gosciniak 1991, S. 215; Odenthal 1992, S. 339-340, 355. Corbusier hat in seinen Reisetagebüchern den Besuch in Edirne sehr genau beschrieben; siehe dazu Gresleri 1991, S. 192-196.
} 

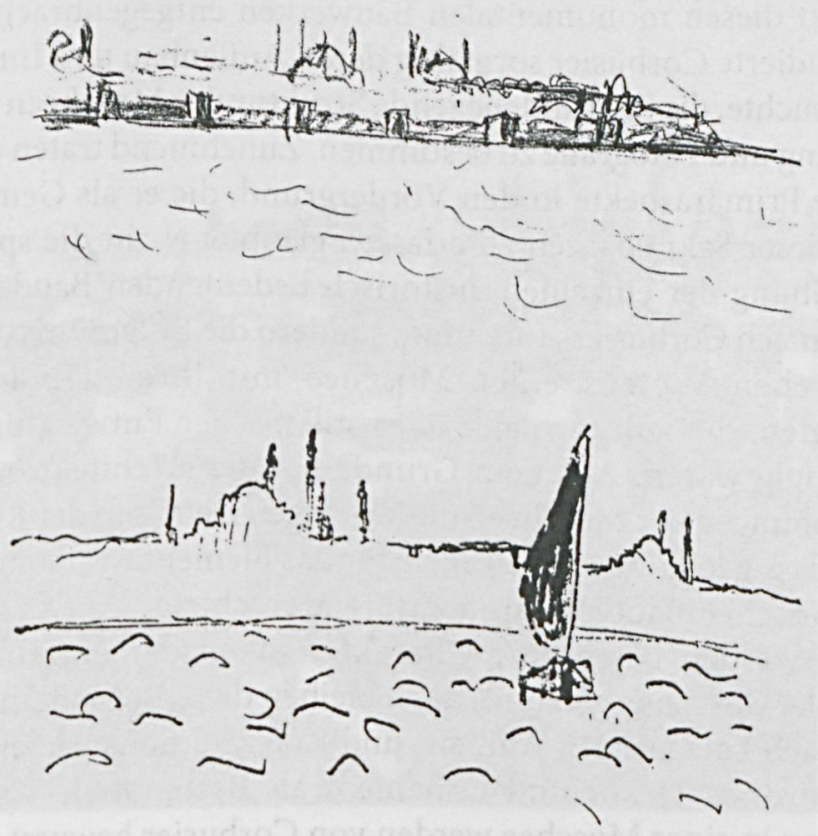

Abb. 1. Le Corbusier: Zeichnungen von Istanbul, 1911 | Paris, Fondation Le Corbusier (nach Gresleri 1991, S. 256).

Interieur, wobei der junge Architekt selbst die Tischdekorationen mit verschiedenfarbigen Blumen präzise beschrieb.

Im Zentrum seiner architektonischen Interessen standen aber eindeutig die Moscheen in den drei türkischen Städten. Und es war dieser historisch bedeutsame Bautypus der islamischen Architektur, auf den er sich in seinen architekturtheoretischen Schriften der 1920er Jahre hauptsächlich bezog, wenn er auf die Baukunst des Orients einging. Ein Zitat aus Corbusiers Reisenotizen kann dies illustrieren: „Ein Nebelschwaden breitete sich über dem Goldenen Horn aus, der sich bis zum Morgengrauen verdichten und Pera und Stambul ertränken wird, außer sie, die unverwundbaren Moscheen. Mit ihrer Basis in einem Meer von Watte trat jede als einzelner, monolythischer Block hervor, abgehoben vom fahlen Himmel der Morgendämmerung. Fast jeden Abend heben sie sich von jenseits des Meeres mit ihren großartigen Silhouetten ab" (Abb. 1). ${ }^{8}$ Hierbei ging es aber nicht nur um den Ausdruck einer emphatisch formulierten Begeisterung, die der junge

${ }^{8}$ Le Corbusier, zit. nach Gresleri 1991, S. 215. 
Architekt diesen monumentalen Bauwerken entgegenbrachte. Vielmehr studierte Corbusier sorgfältig deren Außenbau und Innenraum und versuchte, die zugrundeliegende Struktur der Moscheen in Wort, Zeichnung und Fotografie zu bestimmen. Zunehmend traten architektonische Primäraspekte in den Vordergrund, die er als Gemeinsamkeiten dieser Sakralbauten zu erfassen glaubte. Nicht die spezifische Beschreibung der einzelnen, historisch bedeutenden Baudenkmäler war demnach Corbusiers Intention, sondern die Erkenntnis des architektonischen Wesens einer Moschee mit ihren typologischen Konstanten, die von formaler oder stilistischer Entwicklung völlig unabhängig waren. Aus dem Grunde hat der Architekt bei seinen Beschreibungen der Moscheen die jeweiligen Details in der Regel auch vernachlässigen können, weil er sie für das Elementarverständnis dieses historischen Bautypus als überflüssig erachtete.

Zwar werden bestimmte Charakteristiken der einzelnen Baudenkmäler durchaus genannt, doch bleiben diese Besonderheiten der Suche nach kategorialen Aufbau- und Konstruktionsprinzipien stets untergeordnet. Dekor und Ornament als Bestandteile der Wandgestaltung in einer Moschee werden von Corbusier bewusst missachtet, vor allem, wenn sie erst aus späterer Zeit stammen. Mit scharfen Worten kritisiert er die dekorative Ausstattung und interpretiert sie als „Beleidigung einer gemalten Ornamentation [...], schändlich, abstoßend und empörend ". ${ }^{9}$ Was sich hier bereits ankündigt, ist die radikale Abkehr des Architekten von jeglicher Form der dekorativornamentalen Gestaltung in seinen zukünftigen Entwürfen und Bauprojekten, die er nach seiner Reise in den Orient konzipieren sollte. Die Primäraspekte, die Corbusier bei seinen Beschreibungen der Moscheen demgegenüber hervorhebt, lassen sich mit einfachen Grundbegriffen umschreiben und sollen im Folgenden genauer untersucht werden.

Der erste Aspekt kann mit dem Begriffspaar Monument und Kontext bezeichnet werden. In der städtischen Struktur von Istanbul unterscheidet Corbusier lediglich zwei architektonische Grundelemente: „Stambul ist dichtbesiedelt; jede Behausung des Irdischen ist aus Holz, jede Behausung Allahs ist aus Stein. [...] Es gibt dort nur zwei Arten der Architektur: die großen flachgedrückten, mit ausgebleichten Ziegeln bedeckten Dächer und die gewölbten Hauben der Moscheen mit den daraus hervorbrechenden Minaretten. Friedhöfe

${ }_{9}$ Le Corbusier, zit. nach Gresleri 1991, S. 209. 


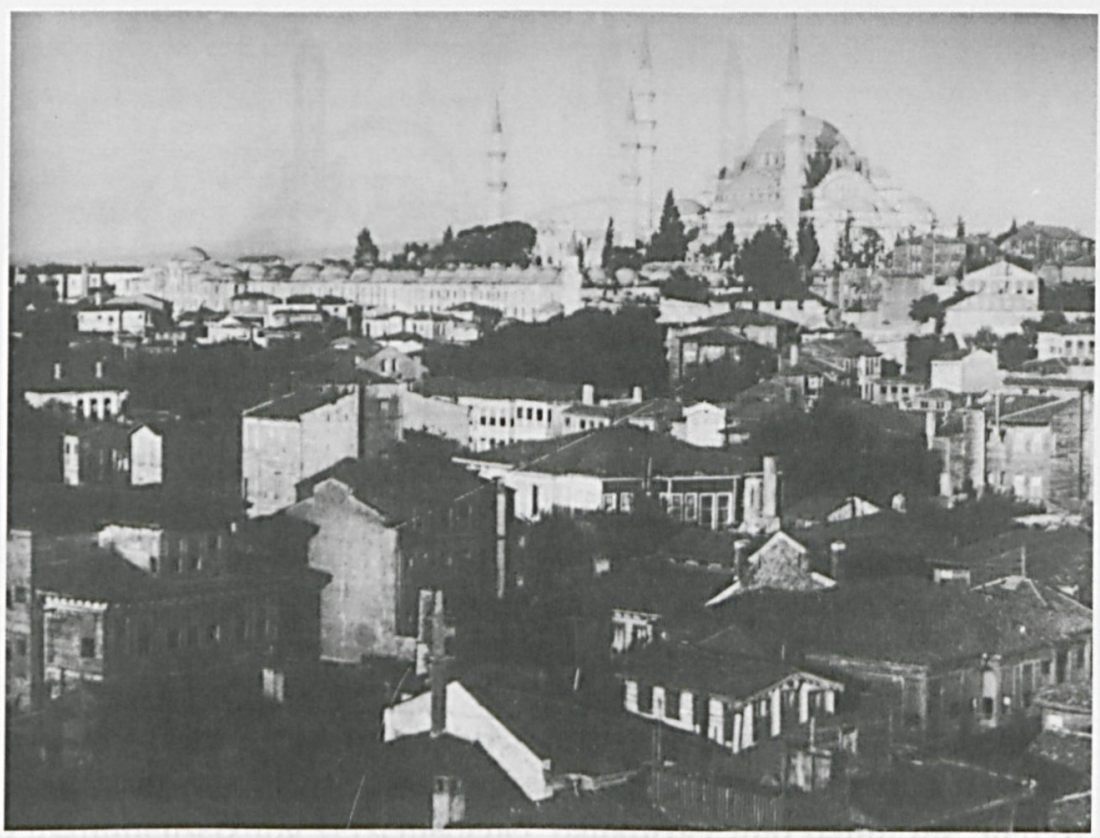

Abb. 2. Le Corbusier: Fotografie von Istanbul, 1911 | Paris, Fondation Le Corbusier (nach Gresleri 1991, S. 259).

verbinden die einen mit den anderen" (Abb. 2). ${ }^{10}$ Und eine weitere Textstelle: „Die Moscheen standen nicht in Einklang mit den mehrstöckigen Häusern aus dunklem $\mathrm{Holz}$ inmitten der dichten Baumgruppen. " ${ }^{11}$ Und über die von Selim II. 1569-74 in Edirne errichtete Selimiye-Moschee: „Sultan Selim' ist für die Stadt wie eine großartige Tiara. "12 Das traditionelle Wechselverhältnis zwischen dem urbanen Monument und der umgebenden Bautextur definiert der Architekt als einen Kardinalunterschied, artikuliert in den Gegensätzen der Baufunktion, des Baumaterials, der Bauformen und der Größendimensionen. Ein Kontrast zwischen dem repräsentativen Sakralbau und dem anonymen profanen Baugewebe ist also der prägende Eindruck, den Corbusier von seinen unterschiedlichen Stadtansichten erhält. Zudem wird in der Vorstellung des Architekten Istanbul durch

${ }^{10}$ Le Corbusier, zit. nach Gresleri 1991, S. 205-206.

"Le Corbusier, zit. nach Gresleri 1991, S. 200.

${ }^{12}$ Le Corbusier, zit. nach Gresleri 1991, S. 192. Zur Selimiye-Moschee in Edirne siehe Hoag 1986, S. 176-177; Gresleri 1991, S. 192-193, Anm. 3; Odenthal 1992, S. 358 360; Yerasimos 2000, S. 270-279. 


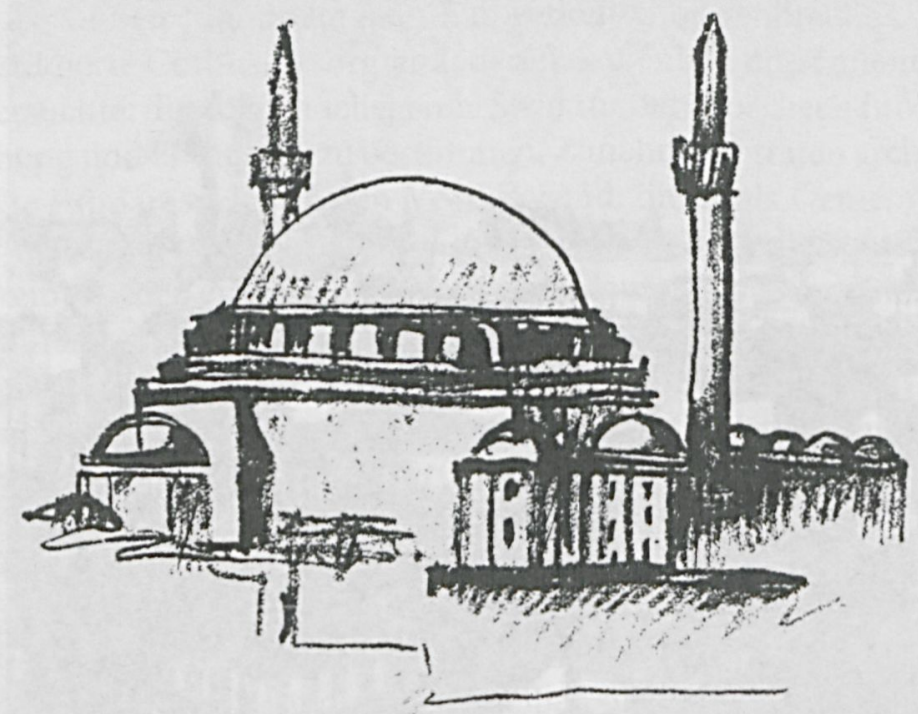

Abb. 3. Le Corbusier: Zeichnung der Moschee Selims I. in Istanbul, 1911 | Paris, Fondation Le Corbusier (nach Gresleri 1991, S. 280).

die vielen Brände in Intervallen immer wieder zerstört, und nur die Moscheen bleiben erhalten: „Man hat es überall erfahren [...], daß es brennt und daß sich Stambul wieder einmal auflöst. Deshalb sagt man auch, daß diese Stadt alle vierzig Jahre eine neue Haut bekommt! Unzerstörbar bleiben nur die großen Moscheen in ihrem Gürtel [...]. Unter der Liebkosung der Flammen schimmern sie wie Alabaster, so rätselhaft wie nie, die unverwundbaren Heiligtümer Allahs!"13 Dass sich Corbusier vor allem für die Moscheen interessiert, ist deshalb auch nicht weiter erstaunlich. Schließlich bilden sie jene isolierten Monumentalbauten, die sich schon alleine durch ihre Form, Größe und Material vom urbanen Umfeld deutlich abheben. Und wenn sich dieser Kontext durch wiederholte Verwüstungen fortwährend verändert, bleiben die Moscheen als dauerhafte und damit zeitlos interpretierbare Fixpunkte im städtischen Erscheinungsbild bestehen.

Der nächste Aspekt, den Corbusier wiederholt erörtert, ist die Stereometrie dieser Baumonumente, die er vor allem in seinen Zeichnungen graphisch hervorhebt (Abb. 3, 4). Wenn die Moscheen in der Stadtgestalt dominieren, dann sind es vor allem ihre Silhouetten, die

\footnotetext{
${ }^{13}$ Le Corbusier, zit. nach Gresleri 1991, S. 206-207.
} 


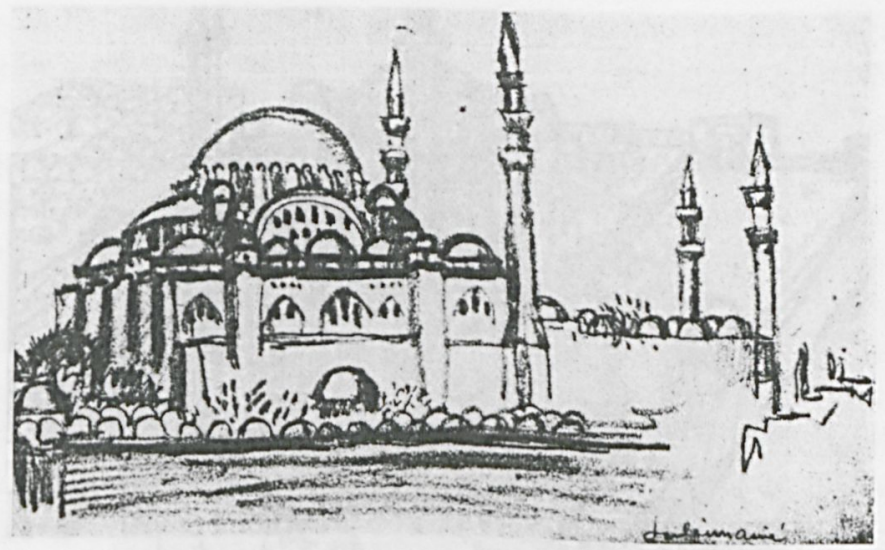

Abb. 4. Le Corbusier: Zeichnung der Moschee Süleymans I. des Prächtigen in Istanbul, 1911 | Paris, Fondation Le Corbusier (nach Gresleri 1991, S. 278).

den optischen Eindruck weithin sichtbar beherrschen. Diese Umrisse resultieren indes aus den Konturen der Bauvolumina, so dass die Zusammensetzung verschiedener Baukörper und damit die Stereometrie beinahe zwangsläufig in den Mittelpunkt der Analyse rücken. Seine entscheidende Erkenntnis hat Corbusier in folgenden Sätzen formuliert: „Eine elementare Geometrie reguliert die Massen: das Quadrat, der Würfel, die Kugel. Auf dem Plan ist es ein rechteckiger Komplex mit einer einzigen Achse. Die Ausrichtung der Achsen aller Moscheen auf islamischem Boden auf den schwarzen Stein der Kaaba ist ein großartiges Symbol der Einheit und des Glaubens. " ${ }^{14}$ Corbusier zufolge beruht die zugrundeliegende Gesetzmäßigkeit eines geometrischen Regulativs auf der wechselseitigen Bezugnahme zwischen wenigen stereometrischen Körpern und einer strengen Axialität, die sich ausnahmslos auf einen Zielpunkt ausrichtet. Aus dem Grunde betont der Architekt in seinen Zeichnungen durch starke Konturlinien die Primärkörper der Moschee-die Halbkugeln der Kuppeln und den Kubus des Unterbaus -, während in der Vogelperspektive die klare Ausrichtung des Gesamtkomplexes hervorgehoben wird (Abb. 5).

Diese exakt artikulierte Stereometrie findet ihre Entsprechung in der besonderen Raumdisposition einer Moschee, ein weiterer Hauptaspekt in Corbusiers Erörterungen. Der unmittelbare Eindruck und damit die optische Wahrnehmung des Architekten spielen hierbei

${ }^{14}$ Le Corbusier, zit. nach Gresleri 1991, S. 210. 


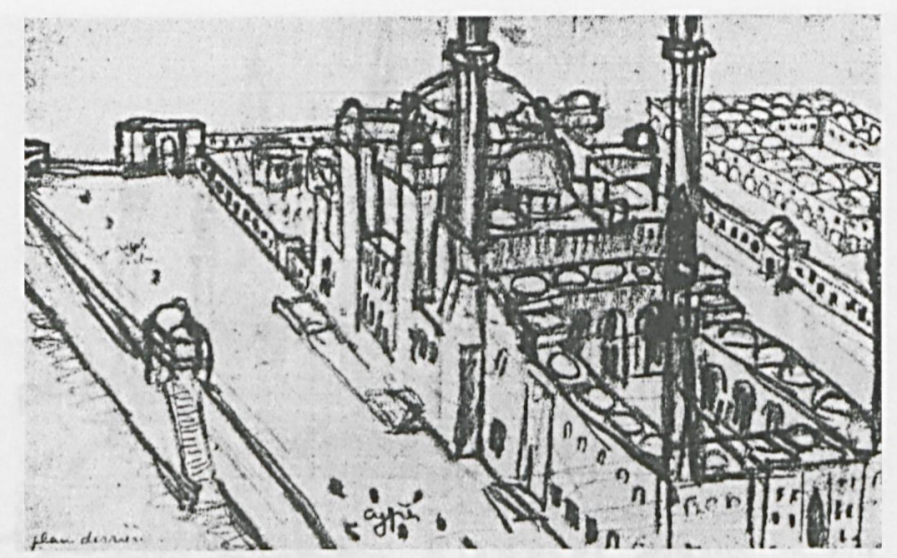

Abb. 5. Le Corbusier: Zeichnung der Moschee Süleymans I. des Prächtigen in Istanbul, $1911 \mid$ Paris, Fondation Le Corbusier (nach Le Corbusier 1982, S. 136, Abb. 1).

eine wichtige Rolle: „[...] und mit einem einzigen Blick sieht man die vier Ecken, man fühlt ihre deutliche Präsenz und man ,baut' so den großen, von kleinen Fenstern durchbrochenen Würfel, von dem sich die vier gigantischen Bogen erheben, die die Pendentifs zusammenführen, nach; man sieht also die durch die tausend kleinen Fenster lichtdurchflutete Kuppelkrone. Darunter befindet sich ein weiter Raum, dessen Form man nicht erfaßt; denn die Halbkugel hat jene Anmut, sich der Meßbarkeit zu entziehen" (Abb. 6, 7). ${ }^{15}$ Der Reduktion auf wenige Primärkörper im Außenbau einer Moschee entspricht im Inneren ein nicht weiter differenzierter Hauptraum, der von einer riesigen Kuppel bekrönt wird. Was Corbusier in diesem Zusammenhang vor allem interessiert, ist das struktive Gerüst, das mit Hilfe von Bögen und Pendentifs die Kuppel zu tragen vermag. Raumeinheit und Konstruktion sind somit die beiden wesentlichen Gesichtspunkte, auf die sich der Architekt bei der Analyse des Innenraumes konzentriert. Damit hängen auch grundsätzliche Fragen der Bautechnik und des Materials zusammen, ebenso wie die teilweise präzisen Analysen von Maßen und Proportionen, die Corbusier als flüchtig notierte Anmerkungen einigen Zeichnungen beifügt.

Ein letzter und wichtiger Aspekt in Corbusiers Beschreibungen der Moscheen bezieht sich auf die Qualität des Lichtes und der Farbe, die er sowohl als einen unmittelbaren Reflex in der Außenerscheinung

${ }^{15}$ Le Corbusier, zit. nach Gresleri 1991, S. 208. 


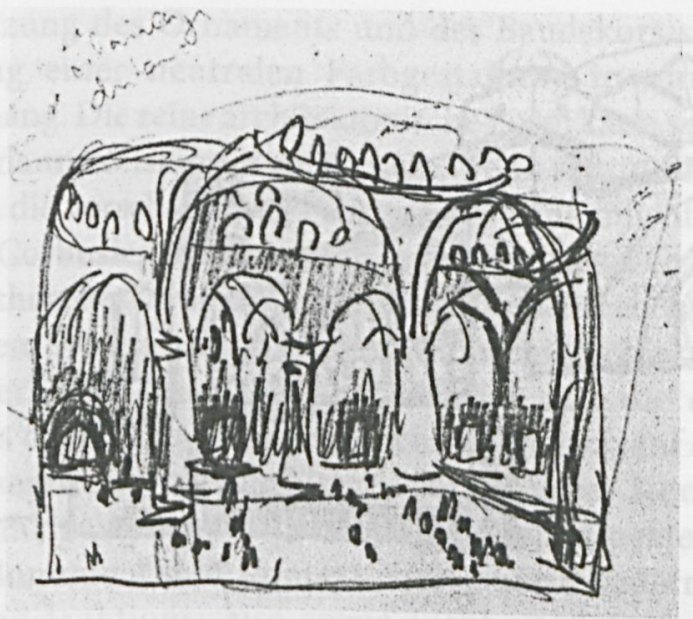

Abb. 6. Le Corbusier: Zeichnung der Moschee Bayazids II. in Istanbul, 1911 | Paris, Fondation Le Corbusier (nach Gresleri 1991, S. 211).

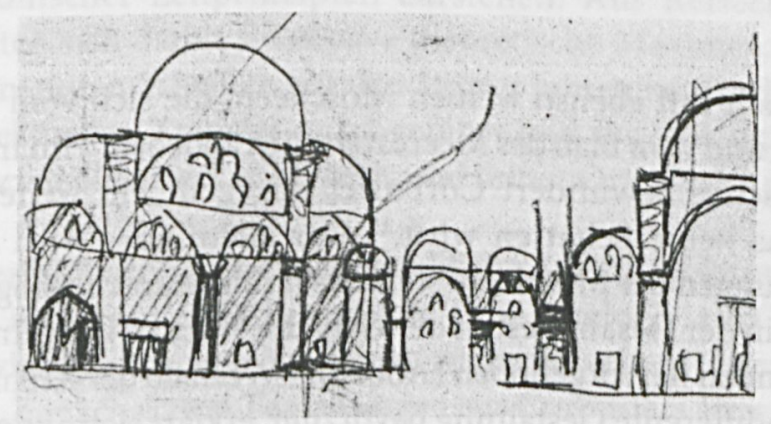

Abb. 7. Le Corbusier: Zeichnung der Moschee Bayazids II. in Istanbul, 1911 | Paris, Fondation Le Corbusier (nach Gresleri 1991, S. 211).

des Gebäudes als auch in dem erstaunlich breiten Spektrum an Variationen und Intensitäten im Innenraum wahrnimmt. In einer Textsequenz spricht Corbusier von einer „lange[n] Schattenlinie, die auf den erloschenen Himmel die Umrisse der großen Moscheen wirft" (Abb. 1). ${ }^{16}$ Die Abfolge der Minarette erscheint ihm „wie ein funkelnder Faden [...] entlang des dunklen Rückens “. ${ }^{17}$ An anderer Stelle imaginiert der Architekt die Vision von Istanbul als einer blendend

${ }^{16}$ Le Corbusier, zit. nach Gresleri 1991, S. 198.

17 Le Corbusier, zit. nach Gresleri 1991, S. 198. 


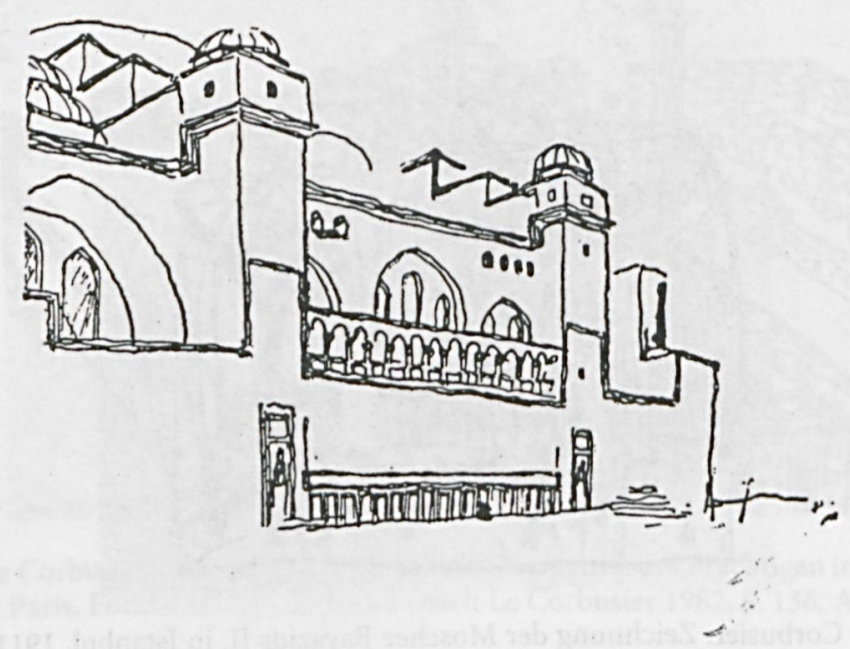

Abb. 8. Le Corbusier: Zeichnung der Moschee Süleymans I. des Prächtigen in Istanbul, 1911 | Paris, Fondation Le Corbusier (nach Le Corbusier 1959, S. 210).

weißen Stadt mit ebenso weißen Moscheen, die sich vom Grün der Zypressen und vom Blau des Meeres deutlich abheben. ${ }^{18}$ Im Innenraum einer Moschee bewundert Corbusier dagegen „ein weites diffuses Licht", das keine Schatten wirft. ${ }^{19}$ Vor allem aber wird in seinen Beschreibungen der Moscheen stets das farblose und homogene Weiß entweder in der Gesamtgestalt der Gebäude oder an ihren Innen- und Außenwänden hervorgehoben (Abb. 8). ${ }^{20}$ Weshalb der Architekt diese farblich indifferente Gestaltung bevorzugt, erklärt sich aus einem einfachen Tatbestand: „All diese Dinge befanden sich unter der Erhabenheit einer Tünche aus weißem Kalk. Die Formen waren klar; die fehlerlose Konstruktion zeigte ihre ganze Kühnheit." ${ }^{21}$ Jede Art der Farbgebung bis hin zur Goldgrundierung würde den elementaren Aufbau und das struktive Gerüst einer Moschee verunklären, zumindest in der persönlichen Vorstellung des Architekten. ${ }^{22}$ Seine völlige

${ }_{18}$ Le Corbusier, zit. nach Gresleri 1991, S. 199.

19 Le Corbusier, zit. nach Gresleri 1991, S. 208.

20 Siehe etwa Le Corbusier, zit. nach Gresleri 1991, S. 194, 199, 201, 203-204, 208$210,235,237$.

${ }^{21}$ Le Corbusier, zit. nach Gresleri 1991, S. 208-209.

${ }_{22} \mathrm{Zu}$ der vom Architekten an manchen Stellen scharf kritisierten Goldgrundierung siehe etwa Le Corbusier, zit. nach Gresleri 1991, S. 199: „Das wäre dann das Ende all dieser pervertierten gelben Farbe, all dieses verfluchten Goldes." 
Geringschätzung des Ornaments und des Baudekors steht mit der Bevorzugung einer neutralen Farbgestaltung in unmittelbarem Zusammenhang. Die reine architektonische Form kann sich Corbusier zufolge erst dann vollständig entwickeln, wenn sich auf ihren weißen Oberflächen die verschiedenen Facetten des Sonnenlichts brechen.

Obgleich Corbusiers Reisenotizen seines, Voyage d'Orient' voll von enthusiastischen Beschreibungen des islamischen Lebens sind, hat er sich bei seinem Studium der Moscheen auf wenige, objektiv nachvollziehbare Merkmale beschränkt. Hier zeigt sich die erstaunliche Fähigkeit des damals noch jungen Architekten, sich auf das Wesentliche zu konzentrieren und die historische Baukunst der osmanischen Moscheen anhand von nur insgesamt fünf Primäraspekten zu charakterisieren: Monument und Kontext, Stereometrie, interne Raumdisposition, Konstruktionsweise sowie Licht- und Farbgebung. Auf seinem weiteren Werdegang vor allem als Theoretiker sollten diese Primäraspekte eine wichtige Grundlage für die Ausarbeitung eigener architektonischer Leitprinzipien darstellen. Aus Reiseeindrücken entwickelten sich damit sukzessive theoretische Maximen. In seinen bereits genannten Schriften aus den 1920er Jahren hat Corbusier diesen intellektuellen Transfer durchgeführt und ihn mit architektonischen Skizzen illustriert, die er während seiner Orientreise gezeichnet hatte..$^{23}$

Der spezifische Inhalt und die sprachliche Ausdrucksform bestimmter Sätze in diesen Schriften geben ihre Analogie zu Corbusiers Studium der islamischen Baukunst während seiner Orientreise zu erkennen. Zunächst zwei Textpassagen aus Corbusiers Vers une architecture von 1923: „Im Raum beobachtet das Auge die vielfachen Oberflächen der Wände und der Gewölbe; Kuppeln bestimmen die Abstände, Gewölbe entfalten Oberflächen; die Pfeiler und die Wände sind nach einleuchtenden Maßstäben angelegt. Das gesamte Gefüge erhebt sich über der Basis und entwickelt sich nach einem Gesetz, das im Grundriß auf die Grundfläche geschrieben war: schöne Formen mannigfaltiger Art, Einheit des geometrischen Prinzips. Tiefwirkende Harmonie: dies heißt Baukunst. ${ }^{24}$ Und weiter: „Die Elemente der Architektur sind Licht und Schatten, Mauer und Raum. [...] Meine Augen sehen etwas, was einen Gedanken verrät. Einen Gedanken, der ohne Worte oder Töne, allein durch die geometrischen Körper klar

\footnotetext{
${ }^{23} \mathrm{Zu}$ Corbusiers Schriften der 1920er Jahre siehe Anm. 4.

${ }^{24}$ Le Corbusier 1982, S. 49.
} 
wird, die in bestimmten Maßverhältnissen zueinander stehen. Diese Körper sind so geformt, daß das Licht jede Einzelheit entschleiert." ${ }^{25}$ In Urbanisme von 1925 schreibt Corbusier: „Die Sintflut: New Yorkdas irdische Paradies: Stambul. [...] In den Kunststädten streben wir dorthin, wo die Formen zusammengehalten sind, um ein Zentrum gruppiert, längs einer Achse geordnet. Horizontalen, prachtvolle Prismen, Pyramiden, Kugeln, Zylinder. Unser Auge sieht sie als reine Formen, und unser entzückter Geist ermißt die Genauigkeit ihrer Zeichnung. ${ }^{26}$ In den zitierten Textsequenzen aus Vers une architecture und Urbanisme verweist Corbusier explizit auf die optische Wahrnehmung als Beleg sowohl für die Relevanz als auch Authentizität des Behaupteten. Der unmittelbare visuelle Eindruck, durch den der damals noch junge Architekt diese Erkenntnisse auf seiner Reise selbst gewonnen hatte, wird zum Garant dafür, dass seine theoretischen Erklärungen eine elementare Bedeutung haben. Die wiederholten Verweise auf das Licht, den Raum, die Achse und die stereometrischen Primärkörper belegen die Herkunft dieser Inhalte aus dem Studium der historischen Baukunst während seiner Orientreise. Und die in die Texte eingefügten Zeichnungen der osmanischen Moscheen illustrieren wiederum seine Theorien. ${ }^{27}$ Noch deutlicher wird der Bezug auf die Reise in Corbusiers L'art décoratif d'aujourd'hui von 1925: „Architektur ist das prachtvolle Spiel der Formen im Licht. Architektur ist ein kohärentes System des Geistes. Architektur hat nichts zu tun mit Dekor. [...] Nach einer solchen Reise ist das Ansehen des Dekors definitiv gesunken. [...] Es ist nicht das Dekor, das die Emotionen des Reisenden auflodern lässt: es ist die Architektur, welche rein und vollständig geformt ist [...]. ${ }^{\text {"28 }}$ Ausdrücklich verweist der Architekt auf seine frühe Orientreise, die die Bedeutung seiner theoretischen Inhalte fundamentieren soll, während er über die damals gewonnenen Eindrücke seinen Verzicht auf jegliche Form von architektonischem Dekor gleich mehrfach legitimiert. ${ }^{29}$

${ }^{25}$ Le Corbusier 1982, S. 134-135.

${ }^{26}$ Le Corbusier 1979, S. 53-54.

${ }^{27} \mathrm{Zu}$ Corbusiers Zeichnungen der osmanischen Moscheen in den beiden Schriften siehe Le Corbusier 1979, S. 53, 55-56, 66, 68; ders. 1982, S. 136-137.

${ }^{28}$ Le Corbusier 1959, S. 211 [deutsche Übersetzung des französischen Originaltextes von Sylvia Scheurer, München]. Auch in dieser Schrift sind Corbusiers Zeichnungen der osmanischen Moscheen abgebildet; siehe etwa S. 168, 210.

${ }^{29}$ Eine ähnliche Kritik am Ornament findet sich auch in Corbusiers 1929 erstmals veröffentlichter Schrift Précisions sur un état présent de l'architecture et de l'urbanisme; siehe dazu Le Corbusier 1964, S. 80. 
In allen drei theoretischen Schriften Corbusiers aus den 1920er Jahren findet seine Orientreise von 1911 ihren Niederschlag. Natürlich sind auch andere persönliche Reiseeindrücke und -erfahrungen aus europäischen Ländern, vorwiegend aus Griechenland und Italien, in diese Theorien eingeflossen. Das Kapitel mit dem Titel „Die Lehre Roms" in Corbusiers Schrift Vers une architecture von 1923 ist hierfür ein aussagefähiges Beispiel. ${ }^{30}$ Dennoch haben die islamische Baukunst und vor allem die Moscheen des osmanischen Reiches einen nachhaltigen Einfluss auf den jungen Architekten ausgeübt, der nicht umsonst den siebenwöchigen Aufenthalt in Istanbul als Höhepunkt seiner Reise bezeichnete. ${ }^{31}$ In der Forschung zu Corbusiers Gesamtschaffen spielt seine Orientreise von 1911 in der Regel nur eine untergeordnete Rolle. ${ }^{32}$ Zwar verwies bereits Sigfried Giedion in seinem 1941 erstmals veröffentlichten Standardwerk Space, Time and Architecture darauf, dass es ,in der Tat eine große Reise, ,un grand voyage, " gewesen sei, die Corbusier damals unternommen hatte. ${ }^{33}$ Dass diese Reise für den weiteren Werdegang des Architekten indessen wichtig war, hat erst Kenneth Frampton in seiner 1980 erstmals publizierten Schrift Modern Architecture in einer zumindest kurzen Sequenz formuliert: „Bevor er [Corbusier, Anm. d. Verf.] jedoch in die Schweiz zurückkehrte, unternahm er eine ausgedehnte Reise durch den Balkan und Kleinasien, und fortan übte die ottomanische Architektur einen stillen, aber nachhaltigen Einfluß auf sein Werk aus. ${ }^{\text {" }}{ }^{34}$ In seiner 1986 veröffentlichten Monographie zum Gesamtwerk des Architekten hat schließlich William Curtis hervorgehoben, dass zur Entdeckung einer Architektur, die dem modernen Zeitalter entsprach, die Orientreise Corbusier neue Orientierungspunkte gegeben habe. ${ }^{35}$ Welche konkreten Auswirkungen auf das architekturtheoretische wie baukünstlerische Schaffen des Architekten sich aus dieser frühen Reise ergeben haben, ist aber von keinem Autor bislang umfassend erörtert worden.

\footnotetext{
${ }^{30}$ Le Corbusier 1982, S. 117-132.

${ }^{31}$ Siehe dazu Anm. 6.

${ }^{32}$ Eine Ausnahme stellen jene Publikationen dar, die sich ausdrücklich mit Corbusiers Orientreise beschäftigen; siehe dazu die in Anm. 1 und 2 angegebene Fachliteratur.

${ }^{33}$ Giedion 1984, S. 328.

${ }^{34}$ Frampton 1991, S. 131.

${ }_{35}$ Curtis 1987, S. 41.
} 


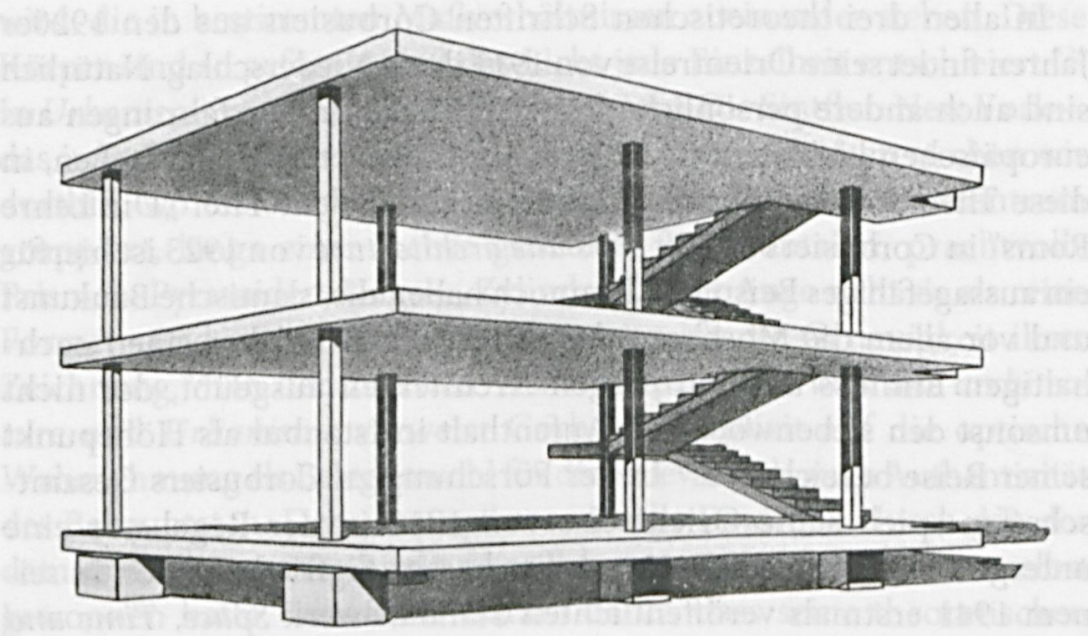

Abb. 9. Le Corbusier: Maison Domino, 1914 | (nach Le Corbusier 1991, S. 23).

Daher stellt sich nun die grundsätzliche Frage, ob Corbusier die durch seine Reiseimpressionen inspirierten und in seinen frühen Schriften artikulierten Theorien bei seinen eigenen Entwürfen auch tatsächlich angewendet hat. Die „Maison Domino“ von 1914 (Abb. 9) und die „Maison Citrohan“ von 1920-22 (Abb. 10) sind berühmte so genannte „Typenstandards", die Corbusier entwickelt und in vielen Projekten verarbeitet hat. ${ }^{36}$ Die Maison Domino ist ein modulares Konstruktionssystem, das auf der Tektonik von Stützen und Lasten basiert, während die Maison Citrohan die geometrisch perfekte Gestalt des Primärkörpers mit glatten, dekorlosen und farblich indifferenten Oberflächen übermittelt. Präzise Konstruktion, exakte Stereometrie und neutrale Farbgebung sind jene Primäraspekte, die Corbusier bei seinen Beschreibungen der osmanischen Moscheen explizit hervorgehoben hat. Der realisierte Höhepunkt, in dem sich die Konstruktionsweise der Maison Domino mit der weißen Primärkörperästhetik der Maison Citrohan verbindet, ist Corbusiers Villa Savoye in Poissy von 1928-29 (Abb. 11). ${ }^{37}$ Auch wenn es zunächst absurd klingen mag; aber diese berühmte Villa Corbusiers, die eine Inkunabel der Klassischen Moderne darstellt, beruht in ihrer puristischen und stereometrisch

${ }^{36}$ Zur Maison Domino und Maison Citrohan siehe Le Corbusier 1991, S. 23-26, $31,45-47$.

${ }^{37} \mathrm{Zu}$ Corbusiers Villa Savoye in Poissy siehe Le Corbusier 1991, S. 186-188. 


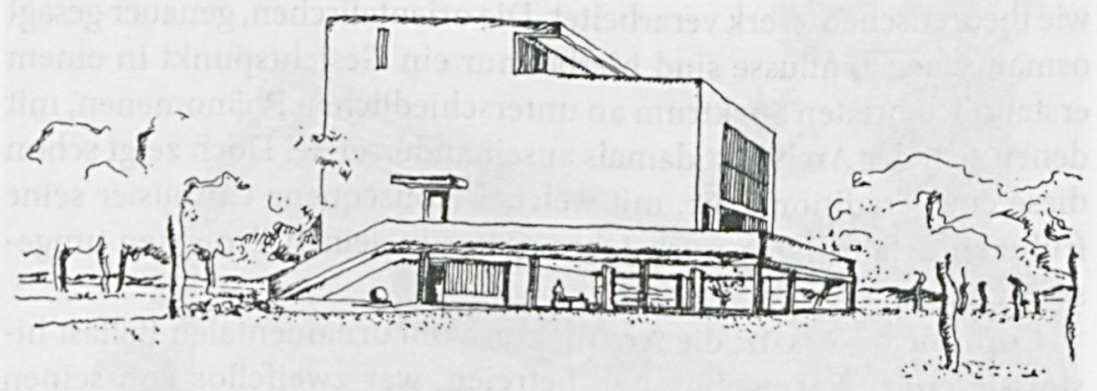

Abb. 10. Le Corbusier: Maison Citrohan, 1922 | (nach Le Corbusier 1991, S. 46).

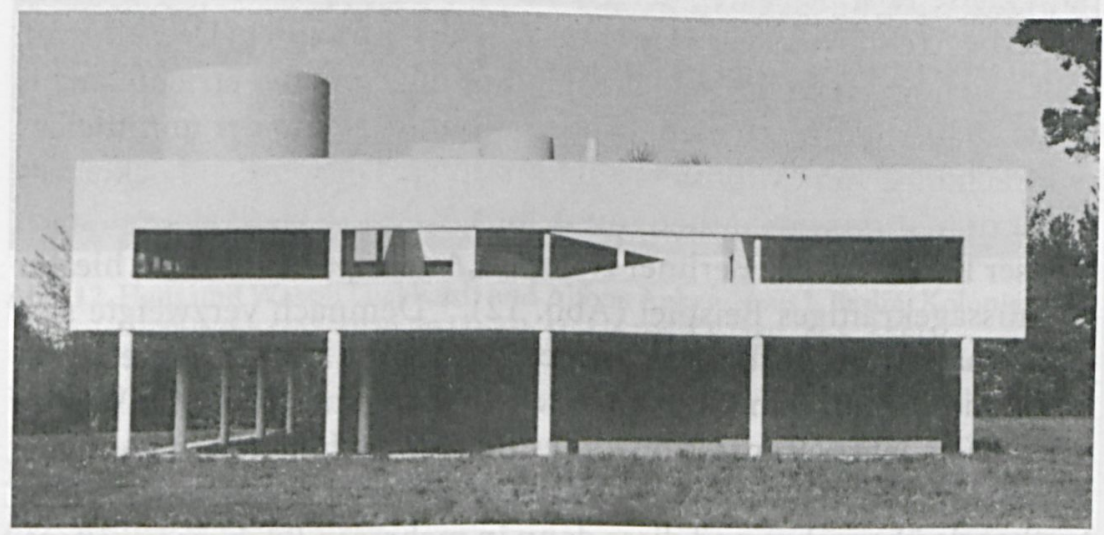

Abb. 11. Le Corbusier: Villa Savoye, Poissy, 1928-29| (nach Curtis 1987, S. 2).

einfachen Gesamterscheinung zu einem nicht unwesentlichen Teil auf jenen Eindrücken, die der Architekt während seiner Orientreise fast zwanzig Jahre zuvor erhalten hatte. Persönliche Überlegungen bei der Betrachtung osmanischer Moscheen sind gewissermaßen als theoretisches Extrakt in die architektonische Gestaltungsweise seiner Bauprojekte der 1920er Jahre eingeflossen.

Doch sollte man methodisch nicht den Fehler machen, diese Entwicklungslinie als ein striktes monokausales Verhältnis von Ursache und Wirkung zu interpretieren. Schließlich handelt es sich lediglich um eine historische Spurensuche, die mit der Reise eines jungen Architekten in den Orient beginnt und bei seinen ersten großen Projekten endet. In diesem Zeitraum hat Corbusier noch eine Vielzahl von prägenden Eindrücken erhalten und in seinem architektonischen 
wie theoretischen Werk verarbeitet. Die orientalischen, genauer gesagt osmanischen Einflüsse sind hierbei nur ein Gesichtspunkt in einem erstaunlich breiten Spektrum an unterschiedlichen Phänomenen, mit denen sich der Architekt damals auseinandersetzte. Doch zeigt schon diese eine Traditionslinie, mit welcher Konsequenz Corbusier seine früheren Erfahrungen noch Jahre später in seinen Projekten umgesetzt hat.

Corbusiers Vorsatz, die Architektur vom ornamentalen Ballast historisierender Formgebung zu befreien, war zweifellos von seinen Reiseeindrücken im Orient beeinflusst. Seine Vorstellungen von einem radikalen Verzicht auf das Dekor führte er in seinen nunmehr purifizierten Bauprojekten der 1920er Jahre exemplarisch vor. Andere moderne Architekten, wie Hans und Wassili Luckhardt in Deutschland, ließen sich von seinem Gedankengut beeinflussen und errichteten bis in die 1930er Jahre vor allem private Wohnhäuser in der unmittelbaren Nachfolge von Corbusiers Baukonzepten. Die von den LuckhardtBrüdern in Zusammenarbeit mit Alfons Anker 1929-30 ausgeführten Häuser I und II in der Berliner Kolonie „Am Rupenhorn“ sind hierfür ein aussagekräftiges Beispiel (Abb. 12). ${ }^{38}$ Demnach verzweigte sich jene zunächst auf Corbusiers eigene Werkgenese konzentrierte Traditionslinie, die mit seiner Orientreise 1911 begonnen hatte, im Verlauf der 1920er Jahre. Impressionen des jungen Architekten, die er nach Jahren der intellektuellen Auseinandersetzung in seine Architekturtheorie übernahm und diese dann in mehreren Büchern veröffentlichte, wurden damit zu einem wichtigen Faktor in der weiteren Entwicklung der modernen Architektur. In dem berühmten, 1932 veröffentlichten Ausstellungskatalog des Museum of Modern Art in New York mit dem Titel The International Style wurde Corbusiers eindeutig formulierter Verzicht auf das Dekor zur Hauptkategorie eines neuen Stilbegriffs erhoben. ${ }^{39}$ Nun war seine Idee eines architektonischen Purismus sozusagen via Definition offiziell etabliert und sollte das internationale Baugeschehen hauptsächlich nach dem Zweiten Weltkrieg mitbestimmen. Und diese weit ausstrahlende Entwicklungslinie hatte im Falle Corbusiers mit dessen frühen

${ }^{38} \mathrm{Zu}$ den Häusern I und II in der Berliner Kolonie „Am Rupenhorn“ siehe Brüder Luckhardt 1990, S. 226-229.

${ }^{39} \mathrm{Zu}$ der von Henry-Russell Hitchcock und Philip Johnson 1932 in New York organisierten Ausstellung „The International Style“ und der im Katalog als Hauptkategorie bezeichneten „Vermeidung aufgesetzter Dekoration“ siehe Hitchcock/Johnson 1985, S. 62-68. 


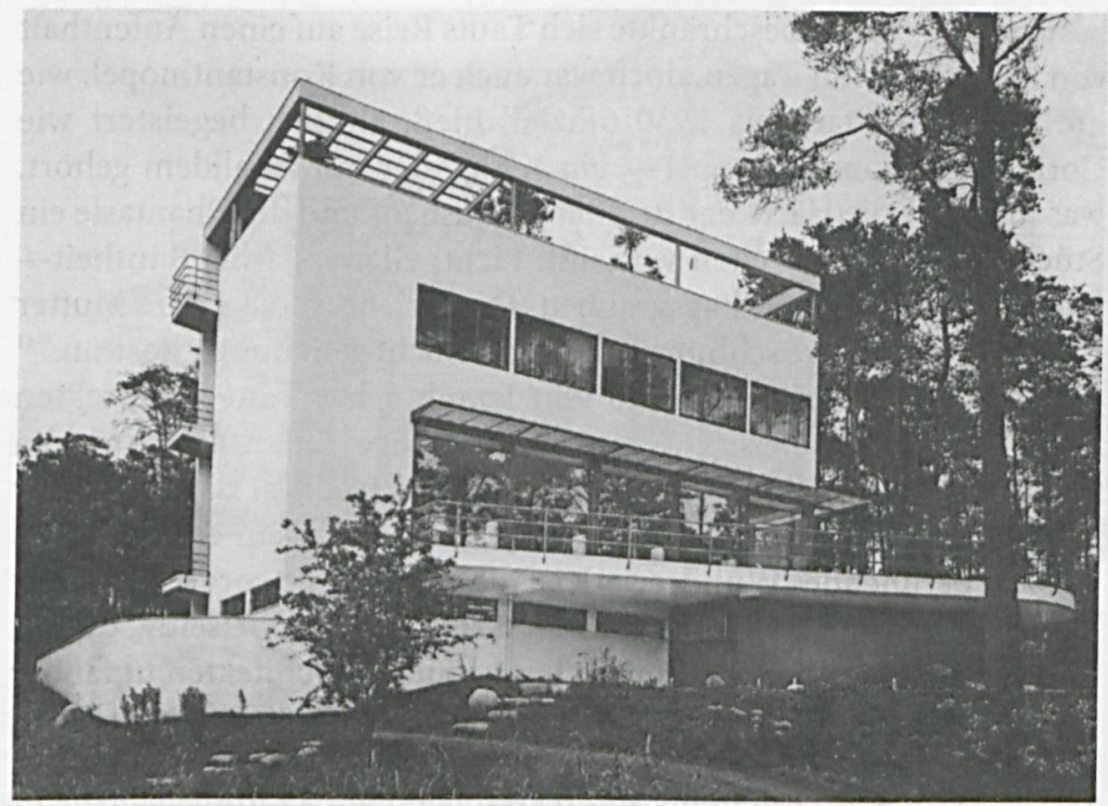

Abb. 12. Hans und Wassili Luckhardt und Alfons Anker: Haus I, Berlin, Kolonie „Am Rupenhorn“, 1929-30 | (nach Hüter 1987, S. 349, Abb. 656).

Reiseerfahrungen im Orient zu Beginn der zweiten Dekade des 20. Jahrhunderts begonnen.

Es ist schon ein merkwürdiger Zufall der Geschichte, dass gerade diejenigen islamischen Monumentalbauten-genauer die osmanischen Moscheen-, die für ihren ornamentalen Reichtum im Innenraum bekannt sind, Corbusiers frühe Absage an das Dekor beeinflusst haben. Wenn man aber zwischen Ornament und Struktur eines Gebäudes in der Weise zu trennen versteht, wie es der junge Architekt bereits 1911 getan hatte, dann wird dieser zunächst widersprüchlich erscheinende Entschluss verständlich und erhält seine eigene Logik. Orientalische Baukunst und europäische Architekturtheorie fanden in Corbusier somit eine neue und ungewohnte Synthese.

Im Kreis jener berühmten Apologeten des Neuen Bauens ist Corbusier in Bezug auf seine Orienteuphorie allerdings kein Einzelfall. Fünf Jahre nach dessen, Voyage d'Orient', genauer gesagt im August 1916, besuchte der deutsche Architekt und Stadtbaumeister Bruno Taut Istanbul, um im Rahmen des Wettbewerbs für das „Haus der Freundschaft" der deutsch-türkischen Vereinigung den Bauplatz zu 
besichtigen. ${ }^{40} \mathrm{Zwar}$ beschränkte sich Tauts Reise auf einen Aufenthalt von lediglich zwölf Tagen, doch war auch er von Konstantinopel, wie die türkische Stadt bis 1930 offiziell hieß, ähnlich begeistert wie Corbusier: „Konstantinopel-, ein Klang, der mit zu alldem gehört, was uns über die Härte der Realität hinaushebt und der Phantasie ein Stück von andern Welten verheißt: Licht, Glanz, Farbe, Buntheitjeden Gegensatz zur Alltagsgrauheit. Der Orient ist die wahre Mutter Europas, und unsere schlummernde Sehnsucht geht immer dorthin. ${ }^{*}{ }^{41}$ Seine persönlichen Eindrücke von Istanbul hat Taut im direkten Anschluss an die Reise in einem nur wenige Seiten umfassenden Artikel veröffentlicht. ${ }^{42}$ Ebenso wie bei Corbusier ist darin von der Moschee als Bautypus die Rede: „[...]-aber welch ein eigenes, ganz auf sich beruhendes Wunderwerk ist die Moschee geworden! Ein sehr klarer Organismus, übersichtlich im Grundriß und vielseitig, delikat und für die Begriffe des europäisch geschulten Architekten unfaßbar in seinem Aufbau. Ein Spiel von Kuppeln, Gesimsen, äußerst feinem Zierat, im Äußeren und im Inneren Helligkeit, Reinheit und Süße. Ungewöhnlich massiv ist die Konstruktion wegen der Erdbebengefahr und wirkt doch leicht. ${ }^{43}$ Und eine weitere Textstelle: „Die ganze Welt des Islams liegt in diesen Bauten. Es gibt nicht vereinzelte Standardwerke ihrer Art, sondern der gleiche Geist durchzieht die größten Moscheen bis zu den kleinsten, die man in dörflicher Umgebung [...] findet. ${ }^{\text {" }}$ Auch Taut hebt die durchdachte Konstruktion, die Intensität der Lichtführung und die Ästhetik einer vom Grundriss regulierten und von Kuppeln beherrschten Stereometrie hervor. Die bereits von Corbusier angesprochene Relation zwischen Monument und Kontext wird von Taut bei seiner Beschreibung der Moscheen ebenfalls thematisiert: „Die großen wieder halten wohl einen Abstand vom profanen Leben, stoßen es aber nicht von sich, sondern ziehen es an, so daß alles, Moschee und das ganze bunte Leben, das nach unsern Begriffen wie ein stilvoller Jahrmarkt ist, eine völlige Einheit bildet. [...] Die großen Moscheen bekrönen die Hügel, dazu das vielfältige

${ }^{40} \mathrm{Zu}$ Tauts Istanbul-Reise siehe Speidel 2007, S. 10-15.

${ }^{41}$ Bruno Taut, zit. nach Speidel 2007, S. 73.

${ }^{42}$ Tauts Artikel mit dem Titel „Reiseeindrücke aus Konstantinopel“ ist in der Zeitschrift Das Kunstgewerbeblatt, 28, 1916/17, Heft 3, S. 49-50, erschienen und erneut abgedruckt worden in Speidel 2007, S. 73-78.

${ }_{43}$ Bruno Taut, zit. nach Speidel 2007, S. 74.

${ }^{44}$ Bruno Taut, zit. nach Speidel 2007, S. 74-75. 


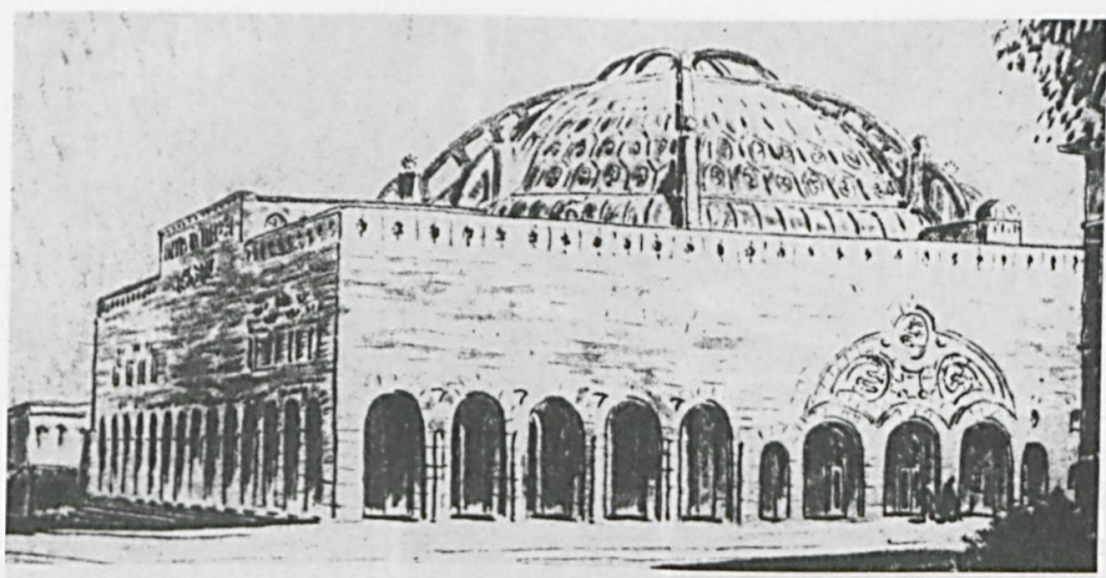

Abb. 13. Bruno Taut: Wettbewerbsentwurf für ein „Haus der Freundschaft“ in Istanbul, 1916 | (nach Junghans 1998, Abb. 75).

Häusergewirr, das immer, so wenig rein und so zusammengewürfelt es auch genannt werden mag, harmonisch klingt [...]. ${ }^{* 45}$

Nur wenige Wochen nach seiner Reise entwarf Taut den architektonischen Beitrag zum Wettbewerb für das "Haus der Freundschaft" (Abb. 13) ${ }^{46}$ Was er konzipierte, entsprach im Außenbau wie Innenraum der allgemeinen Erscheinungsform einer osmanischen Moschee. Statt wie Corbusier die struktiven und formalen Grundbestandteile einer Moschee gewissermaßen zu extrahieren und sie als architektonische Primäraspekte in seine Theorie und Baupraxis einfließen zu lassen, tendierte Taut zu einer orientalisierenden Gestaltungsweise. In der Planung einer von ovalen Glasfenstern durchbrochenen Stahlbetonkuppel, die den kubischen Unterbau bekrönen sollte, zeigt sich aber Tauts ostentative Hervorhebung moderner Baukonstruktion. Drei Jahre nach seiner Reise verfasste Taut einen so genannten Aufruf an die Architekten. ${ }^{47}$ Betitelt war dieser mit einem lateinischen Sinnspruch, der seine immer noch bestehende Orientbegeisterung in prägnanter Formel zusammenfasste: Ex Oriente Lux. ${ }^{48}$

${ }^{45}$ Bruno Taut, zit. nach Speidel 2007, S. 77.

${ }^{46} \mathrm{Zu}$ Tauts Wettbewerbsentwurf siehe Bruno Taut 1980, S. 45, 59, 155; Junghans 1998, S. 31-32; Nerdinger 2001, S. 341; Speidel 2007, S. 13-15.

${ }_{47}$ Tauts Aufruf an die Architekten ist in der Zeitschrift Neue Blätter für Kunst und Dichtung, April 1919, S. 15-17, erschienen und erneut abgedruckt worden in Speidel 2007, S. 101-104.

${ }^{48}$ Bruno Taut, zit. nach Speidel 2007, S. 101. Zu diesem von Taut gewählten lateinischen Sinnspruch siehe auch Pehnt 1998, S. 46-48. 


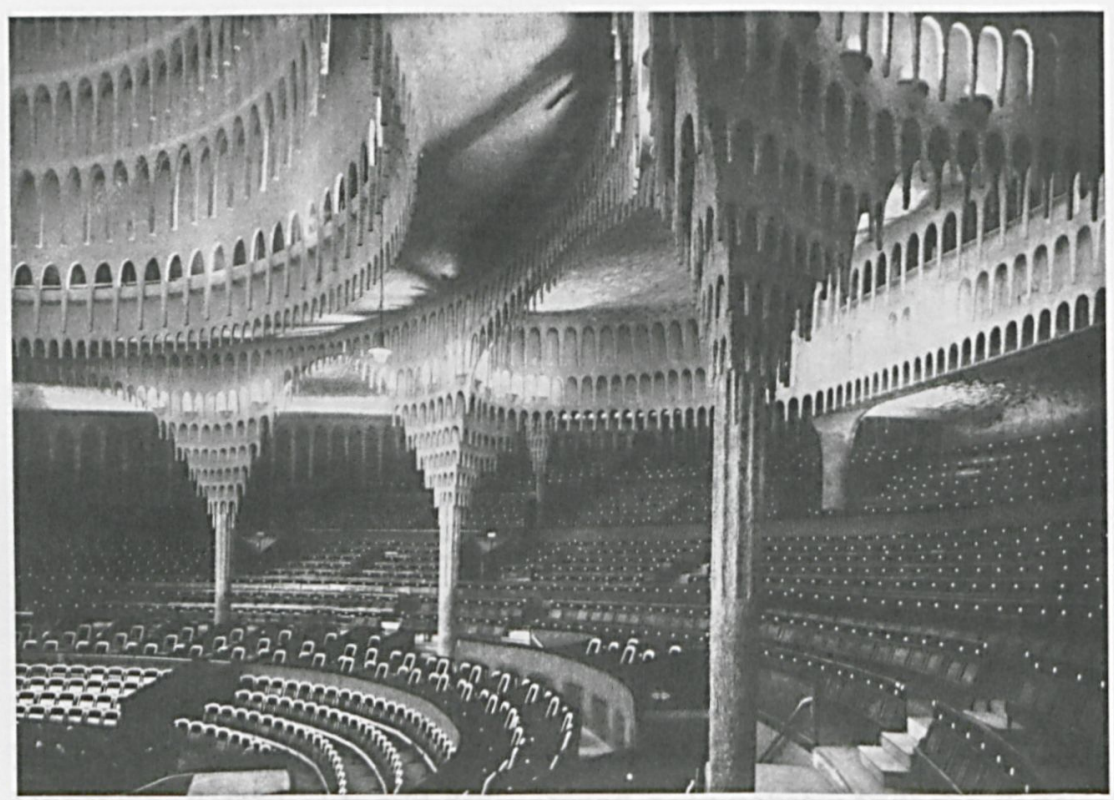

Abb. 14. Hans Poelzig: Großes Schauspielhaus, Zuschauerraum, Berlin, 1918-19| (nach Müller-Wulckow 1929, S. 61).

Im berühmten Großen Schauspielhaus in der Berliner Friedrichstadt, das von dem damals in Dresden tätigen Stadtbaurat und Architekten Hans Poelzig 1918-19 errichtet wurde, zeigt sich eine mit Tauts Vorgehensweise vergleichbare Anlehnung an die islamische Baukunst. ${ }^{49}$ Poelzig hatte sich bei der Gestaltung der außergewöhnlichen Stalaktitenkuppel, die den Innenraum des Zuschauersaals optisch beherrschte, offensichtlich vom Gewölbebau im maurischen Spanien beeinflussen lassen (Abb. 14). Durch frühere Reiseimpressionen wie im Falle Corbusiers oder Tauts waren diese formalen Übernahmen allerdings nicht motiviert. Dennoch teilte Poelzig in gewisser Weise die Orientbegeisterung beider Architekten, als er 1921 in seiner Rede zum geplanten Festspielhaus in Salzburg folgende Sätze formulierte: „Durch Deutschland geht die Scheide zwischen Ost und West. Wir sind das Land der Mitte in Europa. Wir verstehen beide Welten, aber immer, wenn wir uns vom Westen abwandten, wenn wir uns eher der

${ }^{49} \mathrm{Zu}$ Poelzigs Berliner Schauspielhaus und zu dessen formalen Anlehnungen an die islamische, vorwiegend maurische Baukunst siehe Weltkulturen 1972, S. 62-63; Pehnt 1998, S. 252-257. 
mystischen Art des Ostens näherten, waren wir stärker und eigener." ${ }^{50}$ Obgleich der Architekt in seiner Rhetorik weitaus zurückhaltender als der emphatisch argumentierende junge Corbusier war; die Suche nach einer Verbindung von Orient und Okzident ist auch in Poelzigs Worten deutlich vernehmbar.

„Ich denke [...], daß der Eintritt islamischer Baukunst in den Gesichtskreis von Publikum und Künstlerschaft die Wirkung von frischer Zugluft haben wird, die den angesammelten Staub fortbläst und Nerven und Sinne für etwas Neues aufnahmefähig macht. ${ }^{\text {"51 }}$ Dieser Satz des deutschen Architekturhistorikers und -kritikers Adolf Behne aus seinem 1916 veröffentlichten Artikel über „Unsere Baukunst und das Morgenland“ bringt jenes breitgefächerte Interesse sinnfällig zum Ausdruck, das vor allem moderne Architekten in den ersten beiden Jahrzehnten des 20. Jahrhunderts der islamischen Baukunst entgegenbrachten. Als anerkannter Wortführer der Reformbewegung und des Neuen Bauens reagierte Behne nicht nur sensibel auf Entwicklungen im zeitgenössischen Baugeschehen, sondern war auch mit den neuen Architekturtheorien zweifellos vertraut. Dass er in seinem Artikel die große Inspirationskraft der islamischen Baukunst würdigte, ist deshalb nicht weiter erstaunlich, hat er sich doch auch mit Tauts Wettbewerbsentwurf für Istanbul in einem 1919 veröffentlichten Artikel näher beschäftigt. ${ }^{52} \mathrm{Nicht}$ ahnen konnte er damals allerdings, mit welcher Intensität sich der Einfluss der islamischen, vorwiegend osmanischen Baukunst auf Corbusiers architektonischen Schaffensprozess auswirken sollte. Und in hohem Maße erstaunt wäre er vermutlich darüber gewesen, dass sich dieser islamische Einfluss gewissermaßen als theoretisches Extrakt im International Style der späten 1920er und frühen 1930er Jahre etablierte.

Es erscheint nun wie eine böse Ironie der Geschichte, dass man zur Zeit der nationalsozialistischen Herrschaft diesen islamischen Einfluss auf die moderne Architektur scheinbar viel deutlicher zu spüren vermochte. Die Stuttgarter Weißenhofsiedlung von 1927, die mit ihren weißen, flachgedeckten Kuben als frühes Manifest einer internationalen Übereinkunft im Neuen Bauen gilt, wurde bereits 1932 wegen

${ }^{50}$ Hans Poelzig, zit. nach Posener 1994, S. 161.

51 Adolf Behne, zit. nach Speidel 2007, S. 149.

52 Adolf Behnes Artikel über Bruno Taut ist in der Zeitschrift Neue Blätter für Kunst und Dichtung, April 1919, S. 13-15, erschienen und erneut abgedruckt worden in Speidel 2007, S. 155-158. 


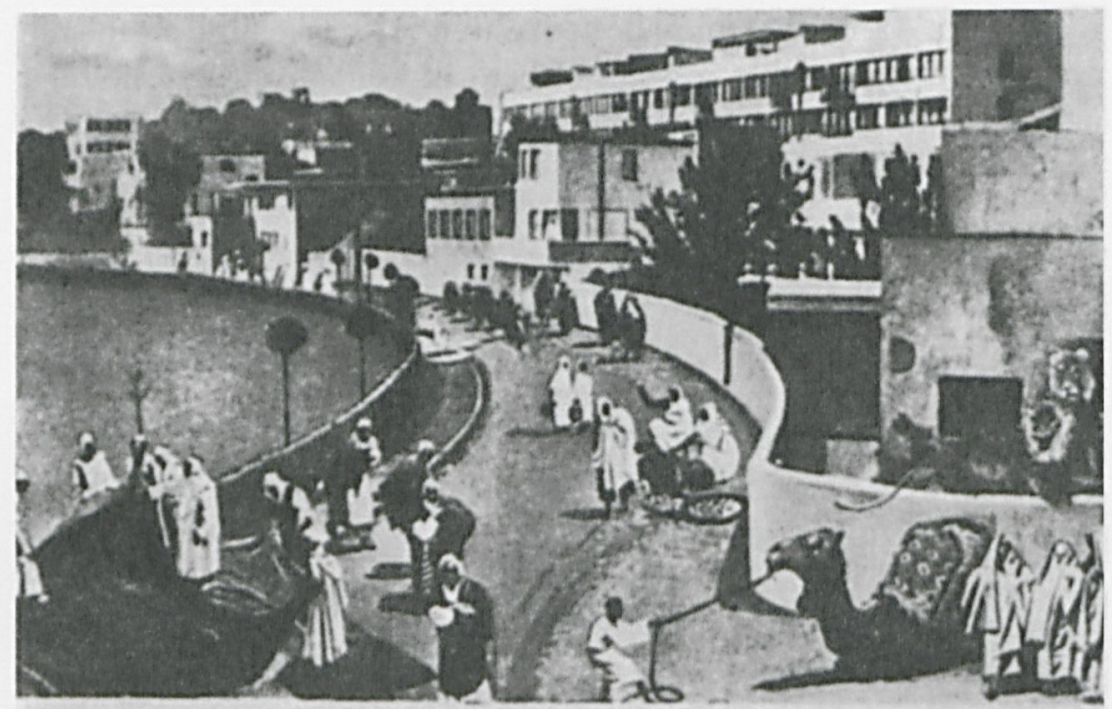

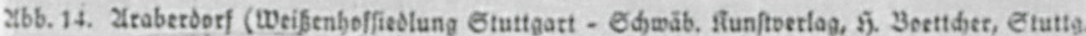
(Dol. Ed)w, 5). 23, 1934, abb, 132)

Abb. 15. Fotocollage, Weißenhofsiedlung Stuttgart, "Araberdorf“, 1934 | (nach Exotische Welten 1987, S. 33).

ihrer „orientalischen Imitationen“ heftig kritisiert. ${ }^{53}$ Zwei Jahre später kam eine Fotocollage in Umlauf, die mit Bildfragmenten orientalischer Lebensweise die Gesamtgestalt der Siedlung auf polemische Weise persiflierte (Abb. 15). Betitelt war diese Collage mit einem ebenso simplen wie einprägsamen Begriff-_Araberdorf“. Der Urheber dieser eher einfältigen Bildkarikatur war sich wohl kaum bewusst, dass er damit einen Gedanken aufgegriffen hatte, mit dem sich Corbusier seit seiner Orientreise 1911 immer wieder beschäftigte: eine Synthese zwischen Orient und Okzident zu schaffen, und das im Medium einer dezidiert modernen Formgebung.

\section{Bibliographie}

Brüder Luckhardt 1990 Brüder Luckhardt und Alfons Anker, Ausst.kat., hg. v. der Akademie der Künste Berlin, Berlin 1990 (Schriftenreihe der Akademie der Künste, 21).

${ }^{53} \mathrm{Zu}$ dieser Kritik an der Stuttgarter Weißenhofsiedlung und zu der im Folgenden genannten Fotocollage siehe Kirsch 1987, S. 206-207 mit Abb.; Exotische Welten 1987, S. 33 mit Abb. 
Bruno Taut 1980

Curtis 1987

Exotische Welten 1987

Frampton 1991

Giedion 1984

Gosciniak 1991

Gresleri 1991

Hitchcock/Johnson 1985

Hoag 1986

Hüter 1987

Jencks 2000

Junghans 1998

Kirsch 1987

Kries 2008

Le Corbusier 1959

Le Corbusier 1964

Le Corbusier 1979

Le Corbusier 1982

Le Corbusier 1987a

Le Corbusier 1987b

Le Corbusier 1991

Müller-Wulckow 1929
Bruno Taut 1880-1938, Ausst.kat., hg. v. der Akademie der Künste Berlin, Berlin 1980 (Akademie-Katalog, 128).

William Curtis: Le Corbusier. Ideen und Formen, Stuttgart 1987 (Originalausgabe Oxford 1986).

Exotische Welten. Europäische Phantasien, Ausst.kat., hg. v. Institut für Auslandsbeziehungen und dem Württembergischen Kunstverein, Stuttgart 1987.

Kenneth Frampton: Die Architektur der Moderne. Eine kritische Baugeschichte, 4. Aufl., Stuttgart 1991 (Originalausgabe London 1980).

Sigfried Giedion: Raum, Zeit, Architektur. Die Entstehung einer neuen Tradition, 3. Aufl., Zürich/München 1984 (Originalausgabe Cambridge/Mass. 1941).

Hans-Thomas Gosciniak (Hg.): Kleine Geschichte der islamischen Kunst, Köln 1991.

Giuliano Gresleri: Le Corbusier. Reise nach dem Orient. Unveröffentlichte Briefe und zum Teil noch nicht publizierte Texte und Photographien von Édouard Jeanneret, Zürich 1991.

Henry-Russell Hitchcock und Philip Johnson: Der Internationale Stil 1932, Braunschweig 1985 (Bauwelt Fundamente, 70).

John D. Hoag: Islam, Stuttgart 1986 (Weltgeschichte der Architektur).

Karl-Heinz Hüter: Architektur in Berlin 1900-1933, Dresden 1987.

Charles Jencks: Le Corbusier and the Continual Revolution in Architecture, New York 2000.

Kurt Junghans: Bruno Taut 1880-1938. Architektur und sozialer Gedanke, 3. Aufl., Leipzig 1998.

Karin Kirsch: Die Weissenhofsiedlung. Werkbund-Ausstellung „Die Wohnung“-Stuttgart 1927, Stuttgart 1987.

Mateo Kries (Hg.): Le Corbusier. Studie über die deutsche Kunstgewerbebewegung, Weil am Rhein 2008.

Le Corbusier: L'art décoratif d'aujourd'hui, Reprint-Ausg., Paris 1959 (Collection de "L'Esprit Nouveau").

Le Corbusier 1929. Feststellungen zu Architektur und Städtebau, Berlin/Frankfurt a. M./Wien 1964 (Bauwelt Fundamente, 12).

Le Corbusier. Städtebau, hg. v. Hans Hildebrandt, 2. Aufl., Stuttgart 1979.

Le Corbusier 1922. Ausblick auf eine Architektur, 4. Aufl., Braunschweig/Wiesbaden 1982 (Bauwelt Fundamente, 2). Le Corbusier. Le Voyage d'Orient, 2. Aufl., Marseille 1987. Ch.-E. Jeanneret Le Corbusier. Voyage d'Orient. Carnets. Reisetagebücher 1910/11, München 1987.

Le Corbusier et Pierre Jeanneret. Euvre complète 1910-1929, hg. v. W. Boesiger und O. Stonorov, 13. Aufl., Zürich 1991. Walter Müller-Wulckow: Deutsche Baukunst der Gegenwart. Bauten der Gemeinschaft, Königstein i. T./Leipzig 1929 (Die Blauen Bücher). 
Nerdinger 2001

Odenthal 1992

Pehnt 1998

Posener 1994

Speidel 2007

Weltkulturen 1972

Yerasimos 2000

Žaknić 1987
Winfried Nerdinger (Hg.): Bruno Taut 1880-1938. Architekt zwischen Tradition und Avantgarde, Stuttgart/München 2001.

Johannes Odenthal: Istanbul. Bursa und Edirne, 2. Aufl., Köln 1992.

Wolfgang Pehnt: Die Architektur des Expressionismus, Ostfildern 1998.

Julius Posener: Hans Poelzig. Sein Leben, sein Werk, Braunschweig/Wiesbaden 1994.

Manfred Speidel (Hg.): Bruno Taut. Ex Oriente Lux. Die Wirklichkeit einer Idee, Berlin 2007.

Weltkulturen und moderne Kunst, Ausst.kat., hg. v. Organisationskomitee für die Spiele der XX. Olympiade München 1972, München 1972.

Stèphane Yerasimos: Konstantinopel. Istanbuls historisches Erbe, Köln 2000.

Ivan Žaknić (Hg.): Le Corbusier. Charles-Édouard Jeanneret. Journey to the Past, Cambridge, Mass./London 1987. 